\title{
Comparative study of the in vitro characteristics of osteoblasts from paralytic and non-paralytic children
}

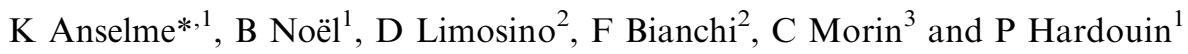 \\ ${ }^{1}$ Institut de Recherche sur les Biomatériaux et les Biotechnologies (IR2B), Université du Littoral Côte d'Opale, Berck \\ sur mer, France; ${ }^{2}$ Laboratoire d'Analyses Médicales, Institut Calot, Groupe Hopale, Berck sur mer, France; ${ }^{3}$ Service \\ d'Orthopédie et de Chirurgie Réparatrice de l'Enfant, Institut Calot, Groupe Hopale, Berck sur mer, France
}

\begin{abstract}
Study design: Cerebral palsy is known to provoke a high loss of bone in children and adults. The potential interest of human osteoblastic cell culture for assessing the osteoblastic function in metabolic bone disorders has been demonstrated by many previous studies. Few studies have attempted to evaluate the capacities of osteoblasts isolated from immobilized or normal bones by in vitro culture methods. Moreover, a few teams did make the distinction between young spastic and flaccid patients.

Objectives: We attempted to characterize mature osteoblasts (OB) and bone marrow-stromal cells (BM) originating from 56 immobile and normal children. Spastic and flaccid patients formed the paralytic group.

Setting: France.

Methods: Osteoblasts and bone marrow cells were isolated from iliac crests obtained during pelvic osteotomies of young control and paralytic patients. The in vitro viability, proliferation and differentiation parameters of the cells from paralytic patients were compared with those of cells coming from normal controls.

Results: No significant differences in the cell proliferation parameters were observed between the two groups. Only initial cell viability before inoculation was lower for the paralytic group, compared to the control group. On the other hand, contrary to expectations, we found that fresh and thawed $\mathrm{OB}$ cells from flaccid patients synthesized more osteocalcin and more collagen respectively than those of the spastic and control groups. Opposite results were obtained from BM cultures.

Conclusion: A negative feedback mechanism by systemic or local factors, which is not conserved in vitro but controls the in vivo osteocalcin and collagen synthesis of flaccid paralytic OB cells, is hypothesized. Because these flaccid patients are known to have a high fat/lean mass, we suggest that leptin may be the potential regulating factor implicated in the hypothesized negative feedback mechanism.
\end{abstract}

Spinal Cord (2000) 38, 622-629

Keywords: bone; osteoblast; bone marrow stromal cells; paraplegia; children

\section{Introduction}

Cerebral palsy is known to provoke a marked bone loss. ${ }^{1-5}$ The causes of this osteopenia are likely to be multiple and include: immobilization, poor nutrition, low calcium intake and anticonvulsant medication. ${ }^{2}$ Osteopenia has been assessed by means of dual energy X-ray absorptiometry (DEXA) by several authors. ${ }^{1,2,5}$ The bone mineral density (BMD) of children and adolescents with spastic cerebral palsy was generally below that of their age-matched normal controls. Ambulatory status was the factor that best correlated

*Correspondence: $\mathrm{K}$ Anselme, Institut de Recherche sur les Biomatériaux et les Biotechnologies (IR2B), Université du Littoral Côte d'Opale, 52 rue du Dr Calot, 62608 Berck sur mer, France with BMD, followed by nutritional status. ${ }^{2}$ Some authors related this osteopenia to the high prevalence of low vitamin D levels in severely handicapped children and adolescents ${ }^{4}$ although others failed to demonstrate any correlation between serum vitamin D levels and $\mathrm{BMD}^{2}$ or between nutrition and growth parameters. $^{3}$ Moreover, serum levels of calcium, phosphate, alkaline phosphatase and osteocalcin were not reliable indicators of low BMD. ${ }^{2}$

Although the physiopathological mechanism behind osteopenia is not really the same, paralytic patients with spinal cord injuries (SCI) also show a loss of bone in areas located below the lesion caused by an early increase of bone remodeling. ${ }^{6-8}$ This osteoporo- 
sis is also characterized by lower bone mineral content (BMC), bone mineral density (BMD), decreased trabecular bone volume (TBV) ${ }^{9}$ and an increased osteoclastic resorption surface. ${ }^{6}$ These changes are accompanied by changes in the biochemical markers. Bone resorption markers (pyridinoline, type I collagen telopeptides, hypercalciuria, hydroxyproline excretion) ${ }^{10-12}$ generally increase after spinal cord injury, whereas bone formation markers (osteocalcin, alkaline phosphatase and procollagen I peptides $)^{13-15}$ generally reduce.

Bone osteopenia can also be seen after other types of immobilization, such as manned space missions, patients confirmed to bed through illness ${ }^{16}$ or experimentally-immobilized animals. ${ }^{97,18}$ In these cases, re-mobilization led to recovery of bone over several weeks, even though the recovery period sometimes took longer than the period of loss.

To our knowledge, few studies have attempted to evaluate the capacities of osteoblasts isolated from immobilized or normal bones by in vitro culture methods. Some experiments carried out on unloaded rats compared the findings of histomorphometric analysis of bone tissue to the in vitro culture of osteoblastic and bone marrow-derived cells. ${ }^{18}$ Moreover, a few teams did make the distinction between young spastic and flaccid patients. ${ }^{19,20}$ However, to our knowledge, none of them studied the in vitro characteristics of their bone-derived cells.

In this preliminary study, we attempted to characterize the phenotype of mature osteoblasts (OB) and bone marrow-stromal cells (BM) originating from both immobile and normal children. To determine if the reduced bone formation generally observed in immobile patients ${ }^{2,5}$ was associated with deficient $\mathrm{OB}$ or $\mathrm{BM}$ capacities, we compared their in vitro viability, proliferation and differentiation parameters with those of cells coming from normal controls. Also, for the first time, a distinction has been made between spastic and flaccid patients during study of the in vitro characteristics of osteoblasts.

\section{Materials and methods}

\section{Patients}

Fifty-six patients from 1 to 15 years of age were included in this study (Table 1) between January 1996 and December 1998. Among the 56 patients, there were
25 females and 31 males. The paralytic group contained 23 patients, all non-ambulant. Of these, 16 were spastic and seven flaccid. Thirty-three normal patients formed the control group.

\section{Surgery}

Bone samples were obtained during pelvic osteotomies undertaken to improve the coverage of the femoral head by the acetabulum. A small part of the bony iliac crest must be removed at the end of surgery in order to close without creating tension of the cartilaginous iliac crest. This fragment of bone, usually thrown away, was sent to the research laboratory for culture. Two types of patients were operated on. The non-paralytic ones underwent pelvic osteotomy for developmental dysplasia of the hip or Legg-Perthes-Calvé's disease. The latter patients may have been immobilized for 1-3 months before surgery. In the paralytic group, pelvic osteotomy was performed to stabilize a dislocated or sub-luxated hip. These patients were either spastic (mainly due to cerebral palsy) or flaccid (due to spinal muscular atrophy or myopathic conditions).

Bone age was determined by X-ray of the pelvis following the Oxford method of assessing skeletal maturity. ${ }^{21}$

\section{Cell culture}

Osteoblasts $(O B)$ Primary osteoblasts were obtained from trabecular bone explants prepared from the iliac crest bone harvested during pelvic osteotomy. Cortical bone was separated from trabecular bone before being discarded. The trabecular bone was then minced into $5 \mathrm{~mm}^{3}$ pieces, extensively rinsed by stirring in phosphate buffered saline (PBS), distributed in $100 \mathrm{~mm}$ dishes (about 30 explants/dish) and covered by Dulbecco's modified Eagle's medium (DMEM, Eurobio, Les Ulis, France) containing $10 \%$ foetal bovine serum (FBS) $+2 \mathrm{mM}$ L-glutamin $+50 \mathrm{IU} / \mathrm{ml}$ penicillin $+50 \mu \mathrm{g} / \mathrm{ml}$ streptomycin. The culture medium was changed twice a week and cultures were maintained until confluence (usually about 3 weeks). In the first part of this experiment, we started a retrospective study using cultured cells that had been frozen in liquid nitrogen. In the second part of this experiment, a prospective study was started with cells cultured before and after freezing. Next, comparison of

Table 1 Group sizes

\begin{tabular}{|c|c|c|c|c|c|c|c|c|c|}
\hline & \multicolumn{6}{|c|}{ Osteoblasts } & \multicolumn{3}{|c|}{ Bone marrow cells } \\
\hline & & Fresh cells & & & Thawed cells & & & Fresh cel & \\
\hline & Male & & Iotal & Male & & Iotal & Male & Female & Total \\
\hline Control patients & 10 & 7 & 17 & 8 & 9 & 17 & 9 & 6 & 15 \\
\hline Spastic patients & 2 & 3 & 5 & 7 & 4 & 11 & 2 & 2 & 4 \\
\hline Flaccid patients & 5 & 1 & 6 & 3 & 2 & 5 & 2 & 0 & 2 \\
\hline Total & 17 & 11 & 28 & 18 & 15 & 32 & 13 & 8 & 23 \\
\hline
\end{tabular}


fresh and thawed osteoblasts was systematically carried out to validate the results obtained in the first part of the experiment.

Bone marrow cells (BM) During preparation of the trabecular bone explant for the purpose of obtaining primary osteoblasts, extensive rinsing of explants by PBS enabled separating-out of the bone marrow cells. These cells were recovered by centrifugation and cultured in $\alpha \mathrm{MEM}+15 \% \mathrm{FCS}+10^{-8} \mathrm{M}$ dexamethasone $+2 \mathrm{mM}$ L-glutamin $+50 \mathrm{IU} / \mathrm{ml}$ penicillin $+50 \mu \mathrm{g}$ $\mathrm{ml}$ streptomycin. At confluence, bone marrow-derived cells were immediately used for in vitro characterization.

Proliferation test Immediately after primary culture or after thawing, confluent cells were harvested and counted using an automatic cell counter (Coulter Zl, Coultronics, Margency, France). Viability was measured by the Trypan blue exclusion method before inoculation (VIAB).

Cells were re-suspended in complete DMEM and inoculated in 24 -multiwell plates at $2 \times 10^{4}$ viable cells/ well. Four wells were inoculated for each of the following proliferation periods: $4 \mathrm{~h}$ and $3,7,10,14$, 17, 21 and 24 days for BMC or 31 days for OB. After each proliferation period, cells were harvested by trypsinization and then counted.

The attachment percentage (number of cells attached $4 \mathrm{~h}$ after inoculation divided by the inoculated viable cell number) was also considered as a viability parameter for statistical analysis (ATTA).

The proliferation parameters used for statistical analysis were:

(1) the number of cells at confluence $(\mathrm{CCN})$ fixed at 21 days for the two types of cell.

(2) the number of cells at the end of experiment: determined after 31 days for osteoblasts and 24 days for bone marrow-derived cells, with or without treatment with $1,25(\mathrm{OH})_{2}$ vitamin $\mathrm{D}_{3}$ (respectively FCN/D and FCN/E).

(3) the doubling time (DOUB) which was calculated using the formula:

$$
\text { DOUB }=\ln (2) \times \frac{\mathrm{t}}{\ln \left(\mathrm{N} \quad \mathrm{N}_{0}\right)}
$$

where $\mathrm{N}$ is the final number of cells, $\mathrm{N}_{0}$ the initial number and the time interval between $\mathrm{N}$ and $\mathrm{N}_{0}$.

(4) the area under the proliferation curve evaluated by the least mean square method (AREA).

Differentiation test Cells were inoculated at $2 \times 10^{4}$ cells/well in 24-multiwell plates. Sixteen wells were inoculated for an in vitro differentiation test at the end of the final period, ie after 28 days for OB and 21 days for BM. Eight wells were prepared for measurement of alkaline phosphatase activity and eight wells for a cell count and evaluation of the osteocalcin and type I procollagen synthesis. Thereafter, these 16 wells were rinsed in PBS and recovered by DMEM for OB (or $\alpha \mathrm{MEM}$ for $\mathrm{BM})+\mathrm{SAB} 0.1 \%$ over $24 \mathrm{~h}$. One half of the cells were then treated with calcitriol $\left(1,25(\mathrm{OH})_{2}\right.$ vitamin $\left.\mathrm{D}_{3}\right) 10^{-8} \mathrm{M}$ in culture medium $+\mathrm{SAB} 0.1 \%$ over $48 \mathrm{~h}(/ \mathrm{D})$, while the other half were treated with a control medium containing SAB $0.1 \%$ and only the calcitriol vehicle, i.e. absolute ethanol (/E). After this period, the culture medium was harvested for osteocalcin content evaluation using the Novocal$\operatorname{cin}^{\mathrm{TM}}$ kit (respectively OC/D and OC/E) and for type I procollagen measurement using the Prolagen- $\mathrm{C}^{\mathrm{TM}}$ kit (respectively $\mathrm{COL} / \mathrm{D}$ and $\mathrm{COL} / \mathrm{E}$ ) (Metrabiosystem, Behring, France). Cells were collected by trypsinisation, counted or centrifuged and sonicated for alkaline phosphatase activity evaluation using an Enzyline ${ }^{\mathrm{TM}}$ kit for ALP activity (respectively ALP/D and ALP/E) (CobasMira, Biomérieux, Marcy l'Etoile, France).

\section{Statistical analysis}

Statistical comparisons were carried out between the groups of patients and between male and female groups. These comparisons were undertaken with fresh or thawed osteoblasts. In some cases, patients in the control and paralytic groups were paired by gender and/or age. Only bone age was used for statistical comparison. The effect of the length of immobilization was tested for some control patients. For comparison, paralytic patients were considered as one group (P) and compared to the control group (N) or were divided into flaccid (F) and spastic (S) groups.

All data was analyzed with Systat statistical software $^{\circledR}$ (Evanston, IL, USA). T-tests were undertaken for comparison between genders or between the two groups $(\mathrm{N}, \mathrm{P})$. Analysis of variance was carried out for comparison between the three groups $(\mathrm{N}, \mathrm{S}$, F). The cut-off value for significance was $P=0.05$.

\section{Results}

\section{Clinical factors}

Homogenization of the two groups according to age and gender was attempted. For fresh osteoblastic cells, the mean age was not comparable for the control and paralytic patients. To eliminate this difference, two normal young female patients were excluded from the normal group. In the case of the thawed osteoblasts, the mean age of the females in the spastic group was significantly lower than the mean age of males. This may be related to difficulty in patient recruitment.

Some of the patients in the control group who were operated on for Legg-Perthes-Calvé's disease had been immobilized for 1-3 months before the operation. Through analysis of variance, we tested to see if this period of immobilization might have affected the proliferation and differentiation of osteoblastic cells. No effects caused by the duration of immobilization were observed on cell parameters. 

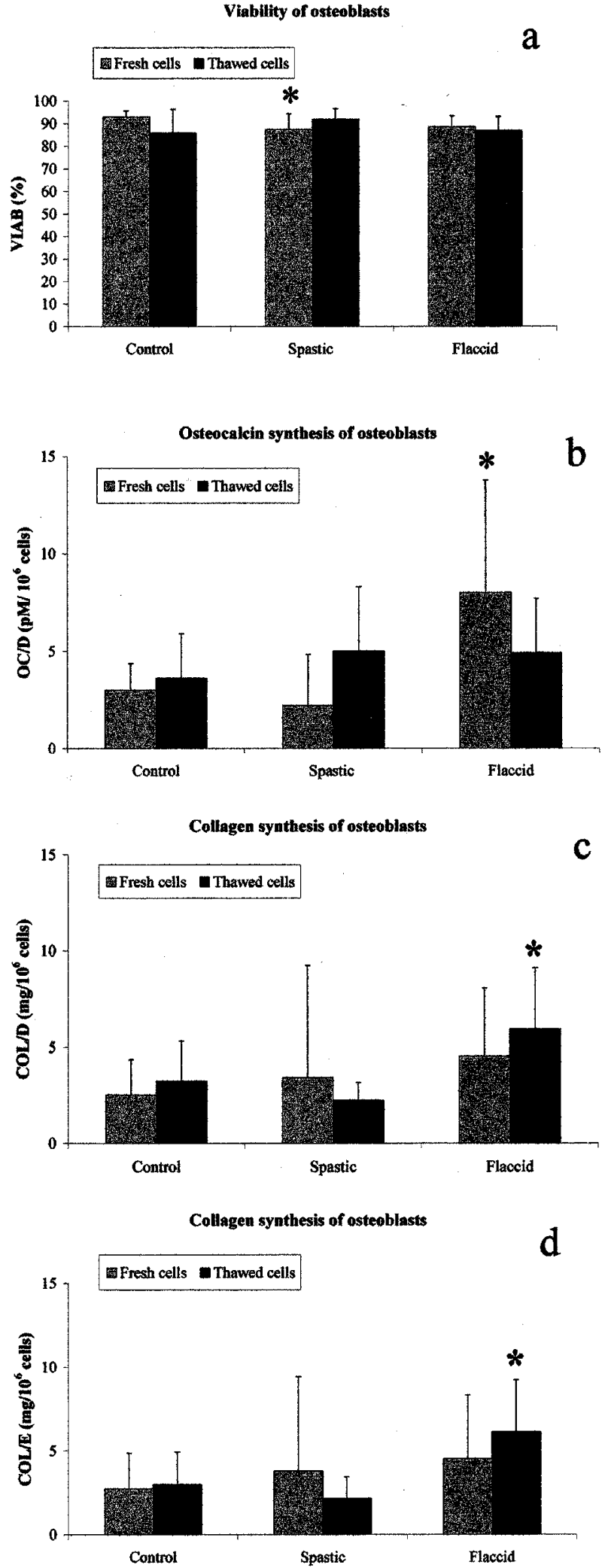

Figure 1 (a) Comparison of viability of fresh and thawed osteoblasts from control, spastic and flaccid groups. *Significantly different from control $(P=0.04)$. (b) Comparison of osteocalcin synthesis of fresh and thawed osteoblasts

\section{Pathology effect}

Osteoblasts This study was carried out on fresh and thawed cells.

For fresh cells, comparison of parameters by analysis of variance for the three groups, control, flaccid and spastic, demonstrated a lower viability for the spastic group compared to the control group $(P=0.04)$ (Figure 1a). The osteocalcin synthesis $(\mathrm{OC} /$ D) by fresh cells in the flaccid group was significantly higher than for cells in the control group $(P=0.01)$ (Figure 1b). No osteocalcin synthesis was obtained without calcitriol stimulation (OC/E). No other significant difference was observed between the three groups.

When the flaccid and spastic patients were grouped together in the same paralytic group $(\mathrm{P})$ and compared to the control group, only cell attachment (ATTA) and initial cell viability (VIAB) were lower in the paralytic group ( $P=0.03$ and 0.019 respectively).

For thawed cells, comparison of the two control and paralytic groups failed to show any difference between parameters. On the other hand, comparison by analysis of variance of the flaccid, spastic and control groups showed a significantly higher collagen synthesis $(\mathrm{COL} / \mathrm{D}$ and $\mathrm{COL} / \mathrm{E})$ for the flaccid group compared to that of the control group $(P=0.032$ and 0.011 respectively) (Figure 1c, d).

Bone marrow-derived cells The $t$-test mean comparison of parameters for the control and paralytic groups showed only a significantly lower collagen synthesis (COL/D and COL/E) by paralytic cells compared to control cells $(P=0.033$ and 0.027 respectively) (Figure 2).

Effect of gender

Gender had no observable effect on the in vitro parameters of the $\mathrm{OB}$ and $\mathrm{BM}$ cells taken from agematched paralytic and non-paralytic patients.

\section{Effect of freezing}

Comparison of the in vitro parameters of fresh and thawed OB was available for 10 patients. As expected, the paired $t$-test demonstrated an inhibition of cell proliferation. The cell doubling time (DOUB) and

from control, spastic and flaccid groups with stimulation by calcitriol (OC/D). *Significantly different from control $(P=0.01)$. (c) Comparison of collagen synthesis of fresh and thawed osteoblasts from control, spastic and flaccid groups with stimulation by calcitriol (COL/D). *Significantly different from control $(P=0.032)$. (d) Comparison of collagen synthesis of fresh and thawed osteoblasts from control, spastic and flaccid groups without stimulation by calcitriol $(\mathrm{COL} / \mathrm{E}) . *$ Significantly different from control $(P=0.011)$ 


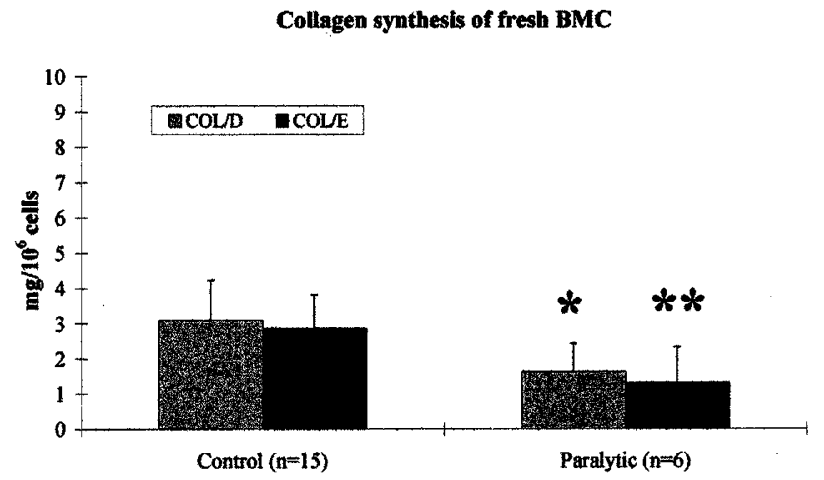

Figure 2 Comparison of collagen synthesis by fresh bone marrow cells from control and paralytic groups with $(\mathrm{COL} /$ D) or without $(\mathrm{COL} / \mathrm{E})$ stimulation by calcitriol. *Significantly different from control $(P=0.033)$. **Significantly different from control $(P=0.027)$

number of cells after 28 days of culture (FCN/D, $\mathrm{FCN} / \mathrm{E})$ was reduced after freezing and thawing $(P=0.024,0.020$, and 0.012 respectively $)$.

Comparison osteoblast/bone marrow-derived cells Comparison of the in vitro parameters of osteoblasts and bone marrow-derived cells concerned 13 patients. The paired $t$-test demonstrated a higher attachment potential (ATTA) for bone marrow-derived cells, compared to osteoblasts $(P=0.046)$ although their initial cell viability was not significantly different $(P=0.718)$.

On the other hand, at the end of culture, bone marrow-derived cells appeared less differentiated than osteoblasts. Their alkaline phosphatase activity (ALP/ E), their osteocalcin (OC/D) and collagen synthesis $(\mathrm{COL} / \mathrm{E})$ were significantly lower (respectively $P=0.02,0.001$, and 0.041) (Figure 3a-c).

\section{Discussion}

We observed differences in the in vitro viability, proliferation and differentiation characteristics between the groups. Cell viability of $\mathrm{OB}$ was lower in the paralytic group than in the control group. More surprisingly, in spite of the small number of patients in the flaccid group, their fresh $\mathrm{OB}$ had a significantly higher osteocalcin synthesis than that of the control or spastic groups. Additionally, we observed increased collagen synthesis by thawed flaccid OB.

The potential interest of human osteoblastic cell culture for assessing the osteoblastic function in metabolic bone disorders has been demonstrated by many previous studies. ${ }^{22-28}$ However, as noted by Marie et $a l,{ }^{29}$ the technique of preparing cells from bone explants can be a source of heterogeneity of cell culture. This heterogeneity can be related to the presence of mixed cells with different growth rates or with various stages of differentiation. ${ }^{29}$ Bone marrow
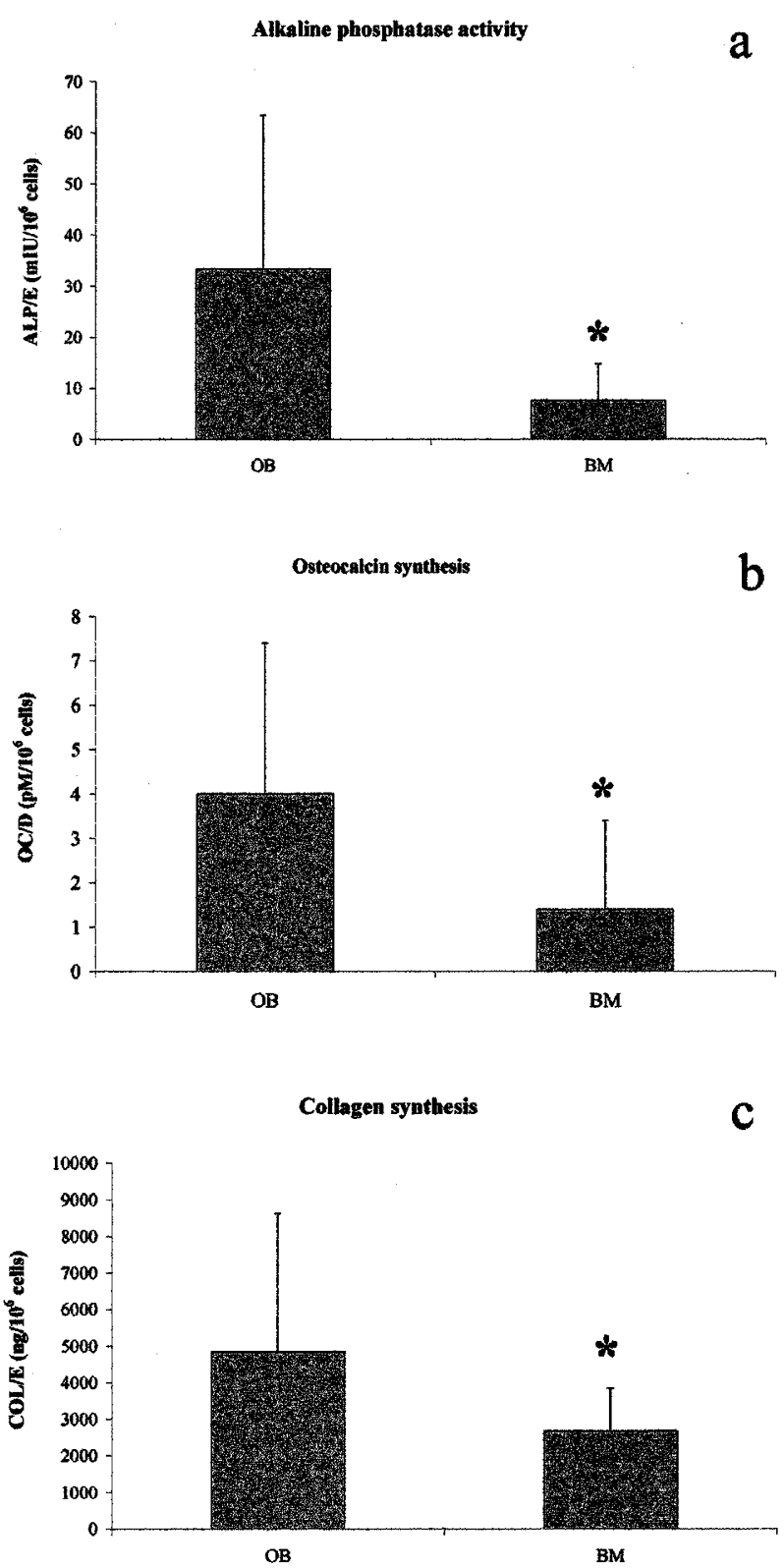

Figure 3 (a) Comparison of osteoblasts (OB) and bone marrow-derived cells (BM) alkaline phosphatase activity without stimulation by calcitriol (ALP/E). *Significantly different from OB $(P=0.020)$. (b) Comparison of osteoblasts (OB) and bone marrow-derived cells (BM) osteocalcin synthesis with stimulation by calcitriol (OC/D). *Significantly different from $\mathrm{OB}(P=0.001)$. (c) Comparison of osteoblasts (OB) and bone marrow-derived cells (BM) collagen synthesis without stimulation by calcitriol (COL/ E). *Significantly different from OB $(P=0.041)$

cells can be present if care has not been taken to eliminate them by collagenase treatment ${ }^{30}$ or by the specific technique of culture of cells from trabecular bone surface. ${ }^{31}$ Osteoblasts obtained from bone explant without any enzymatic digestion have previously been shown to produce heterogenous pheno- 
type of osteoblast in culture. ${ }^{32}$ In our experiment, since we did not proceed to enzymatic digestion, we cannot guarantee that our OB culture was completely free of BM. Since BM is less differentiated than trabecular bone surface-derived $\mathrm{OB}$, the presence in our culture of various relative quantities of BM and OB could explain the difference in our results according to the groups. Paralytic patients have been shown to have less red bone marrow, related to a lower BMC, BMD and $\mathrm{TBV}^{9}{ }^{9}$ in their trabecular bone than that of the control model. However, this hypothesis does not explain the difference between spastic and flaccid patients.

Another explanation for this difference between flaccid and spastic patients may be that the in vivo osteocalcin and collagen synthesis by flaccid paralytic OB cells may be subject to control by a negative feedback mechanism by systemic of local factors, which may be lifted in vitro. Some growth factors are known to have a rather negative effect in vivo on osteocalcin synthesis, such as TGF $\beta$, IL1 or TNF ${ }^{33-35}$ Glucocorticoids are also known to attenuate the increased osteocalcin induced by calcitriol. ${ }^{36-38}$ Since osteoblastic cells in vitro synthesize these growth factors and cytokines, it is more likely to be their regulation that may be modified by in vitro culture conditions. These factors have been shown to be regulated by hormones such as estrogen, androgen, progesterone, parathormone (PTH) or growth hormone but also by glucocorticoids or calcitriol. ${ }^{33-35}$ Some of these regulating factors have been shown to be regulated themselves by leptin, a cytokine produced by white fat and involved in a range of physiological processes (energy homeostasis, fat and glucose metabolism, hemopoiesis, immune function, bone mass regulation). ${ }^{39-42}$ Some authors have recently demonstrated that leptin acts directly on human marrow stromal cells to enhance osteoblasts differentiation. ${ }^{43}$

The recent evidence that leptin inhibits bone formation through a hypothalamic relay ${ }^{42}$ did alert us to the major differences existing between our two paralytic groups. The spastic patients present lesions in the cerebral zone but retain muscular activity. However, the flaccid patients have no lesions of the central nervous system but do not present any muscular activity relative to their myopathy or spinal muscular atrophy. In these conditions, we might suspect the role of relative fat/lean mass in the paralytic patients, which may influence osteoblastic activity and then bone formation through leptin. The lean mass of flaccid patients has been shown to decrease dramatically after spinal cord injury in the paralysed areas, although spastic patients showed a relative conservation of lean mass. ${ }^{19}$ Logically, this decrease in lean mass should be accompanied by an increase in fat mass. This was confirmed by several works. $^{44-47}$ Therefore, a higher fat mass in these flaccid patients could be at the origin of a higher stimulation of the hypothalamus by leptin, thereby inhibiting bone formation in these patients. ${ }^{42}$ Consequently, the $\mathrm{OB}$ cultured from the iliac crests of these flaccid patients and freed from this inhibitory action should have either a higher metabolic activity or a higher sensitivity to calcitriol stimulation in vitro compared to that of spastic or control OB.

Contrary to $\mathrm{OB}$, the BM of the paralytic group did synthesize less collagen than the cells of the control group. In this case, the paralytic patients were too few to differentiate between spastic and flaccid paralytic patients. This could explain the contradictory results between $\mathrm{OB}$ and BM. Alternatively, these contradictory results could be related to the lower differentiation state of the BM. The previously evoked negative feedback mechanism induced by leptin may be not be effective on less differentiated cells like BM.

Further experiments will be needed to determine the fat/lean mass ratio of these patients and to monitor bone formation markers, bone degradation and body adiposity in their serum. A previous study carried out in our hospital concerning the level of these markers in the serum of patients after traumatic brain injury showed a significantly higher serum leptin level when compared to controls after correction for body weight (E Meys, personal communication) although the crude serum leptin level was not significantly modified after trauma. ${ }^{48}$ Moreover, a negative correlation was found between a bone formation marker (serum bone alkaline phosphatase) and serum leptin.

\section{Conclusions}

Despite the lower bone metabolism observed in children with cerebral palsy, we failed to demonstrate lower values of proliferation and differentiation parameters for $\mathrm{OB}$ from paralytic patients compared to control patients. To the contrary, we observed a significantly higher collagen and osteocalcin synthesis by $\mathrm{OB}$ prepared from flaccid patients compared to control or spastic patients. Many reasons may be hypothesized to explain these surprising results. As the method we used to produce OB does not absolutely eliminate all BM, we may assume that our results could be related to survival of one subpopulation of less mature osteoblasts derived from BM in control cells compared to paralytic cell cultures. However, this does not explain the difference between spastic and flaccid patients. It is more likely that $\mathrm{OB}$ cells from flaccid patients may be subject to control by a negative feedback mechanism by systemic or local factors, which may be lifted in vitro. In particular, a good candidate may be leptin. Indeed, a higher fat/lean mass in the flaccid patients may be at the origin of inhibition of bone formation by leptin through a hypothalamic relay. In vitro, the suppression of this inhibition may induce a higher metabolism of flaccid $\mathrm{OB}$ or an increase in their sensitivity to calcitriol stimulation. Further evaluations of the fat/lean mass ratio and of the bone formation, bone degradation and body adiposity markers in the serum of flaccid and young 
spastic paralytic patients are needed to validate this hypothesis.

\section{Acknowledgements}

The authors are grateful to Dr P Marie for the helpful discussions during preparation of the manuscript and Dr A Acharya and Mrs Frances Mary Dymock for the English revision of the manuscript.

\section{References}

1 Shaw NJ, White CP, Fraser WD, Rosenbloom L. Osteopenia in cerebral palsy. Arch Dis Childhood 1994; 71: 235-238.

2 Henderson RC, Lin PP, Greene WB. Bone-mineral density in children and adolescents who have spastic cerebral palsy. $J$ Bone Joint Surg 1995; 77-A: $1671-1681$

3 Henderson RC. Vitamin D levels in noninstitutionalized children with cerebral palsy. J Child Neurol 1997; 12: 443-447.

4 Lee JJK, et al. Disorders of bone metabolism in severely handicapped children and young adults. Clin Ortho Related Res 1989; 245: 297-302.

5 Lin PP, Henderson RC. Bone mineralization in the affected extremities of children with spastic hemiplegia. Dev Med Child Neurol 1996; 38: $782-786$.

6 Minaire $\mathrm{P}$ et al. Quantitative histological data on disuse osteoporosis. Comparison with biological data. Calc Tiss Res 1974; 17: $57-73$.

7 Chantraine A, Nusgens B, Lapiere ChM. Bone remodeling during the development of osteoporosis in paraplegia. Calcif Tissue Int 1986; 38: $323-327$.

8 Uebelhart D, Demiaux-Domenech B, Roth M, Chantraine A Bone metabolism in spinal cord injuried individuals and in others who have prolonged immobilization. Paraplegia 1995; 33: $669-$ 673.

9 Minaire P, Edouard C, Arlot M, Meunier PJ. Marrow changes in paraplegic patients. Calcif Tissue Int 1984; 36: $338-340$.

10 Delmas PD. Biochemical markers of bone turnover for the clinical investigation of osteoporosis. Osteoporosis Int 1993; Suppl. 1: S81 - S86.

11 Vaziri ND, et al. Vitamin D, parathormone, and calcitonin profiles in persons with long-standing spinal cord injury. Arch Phys Med Rehabil 1994; 75: $766-769$.

12 Pietschmann $\mathrm{P}$, et al. Increased serum osteocalcin levels in patients with paraplegia. Paraplegia 1992; 30: 204-209.

13 Roberts D, et al. Longitudinal study of bone turnover after acute spinal cord injury. Clin Endocrinol Metab 1998; 83: 415-422.

14 Uebelhart D, et al. Early modifications of biochemical markers of bone metabolism in spinal cord injury patients. A preliminary study. Scand J Rehabil Med 1994; 26: 197-202.

15 Bauman WA, Zhong YG, Schwartz E. Vitamin D deficiency in veterans with chronic spinal cord injury. Metabolism 1995; 44: $1612-1616$

16 Mazess RB, Whedon GD. Immobilization and bone. Calcif Tissue Int 1983; 35: 265-267.

17 Zhang RW, et al. Rat tail suspension reduces messenger RNA level for growth factor and osteopontin and decreases the osteoblastic differentiation of bone marrow stromal cells. $J$ Bone Miner Res 1995; 10: 415.

18 Machwate $\mathrm{M}$, et al. Skeletal unloading in rat decreases proliferation of rat bone and marrow-derived osteoblastic cells. Am J Physiol 1993; 264: E790-E799.

19 Wilmet E, et al. Longitudinal study of the bone mineral content and of soft tissue composition after spinal cord section. Paraplegia 1995; 33: 674-677.

20 Demirel G, Yilmaz H, Paker N, Onel S. Osteoporosis after spinal cord injury. Spinal Cord 1998; 36: 822-825.

21 Acheson RM. The Oxford method of assessing skeletal maturity. J Anat 1954; 88: 498.
22 Marie PJ, de Vernejoul MC, Connes D, Hott M. Decreased DNA synthesis by cultured osteoblastic cells in eugonadal osteoporotic men with defective bone formation. J Clin Invest 1991; 88: 1167 1172.

23 Lomri A, Marie PJ. Bone cell responsiveness to Transforming Growth Factor $\beta$, Parathyroid Hormone, and Prostaglandin $\mathrm{E}_{2}$ in normal and postmenopausal osteoporotic women. $J$ Bone Miner Res 1990; 5: 1149-1155.

24 Marie PJ, et al. Relationship between histomorphometric features of bone formation and bone cell characteristics in vitro in renal osteodystrophy. J Clin Endocrinol Metab 1989; 69: $1166-1173$.

25 Marie PJ, Sabbagh A, de Vernejoul MC, Lomri A. Osteocalcin and deoxyribonucleic acid synthesis in vitro and histomorphometric indices of bone formation in postmenopausal osteoporosis. J Clin Endocrinol Metab 1989; 69: 272 -279.

26 Mörike $\mathrm{M}$, et al. In vitro expression of osteoblastic markers in cells isolated from a normal fetal and postnatal human bone and from bone of patients with osteogenesis imperfecta. J Cell Physiol 1993; 157: $439-444$

27 de Pollack C, Renier D, Hott M, Marie PJ. Increased bone formation and osteoblastic cell phenotype in premature cranial suture ossification (craniosynostosis). J Bone Miner Res 1996; 11: $401-407$.

28 Silve C, et al. Response to parathyroid hormone and 1,25dihydroxyvitamin D3 of bone-derived cells isolated from normal children with abnormalities in skeletal development. $J$ Clin Endocrinol Metab 1986; 62: 583 - 590.

29 Marie PJ. Human osteoblastic cells: a potential tool to assess the etiology of pathologic bone formation. J Bone Miner Res 1994; 9: $1847-1850$.

30 Robey PG, Termine JD. Human bone cells in vitro. Calcif Tissue Int 1985; 37: $453-460$.

31 Marie PJ, Lomri A, Sabbagh A, Basle M. Culture and behavior of osteoblastic cells isolated from normal trabecular bone surfaces. In Vitro Cell Dev Biol 1989; 25: $373-380$

32 Thavarajah M, Evans DB, Kanis JA. Differentiation of heterogeneous phenotypes in human osteoblast cultures in response to 1,25-dihydroxyvitamin $\mathrm{D}_{3}$. Bone $1993 ; 14: 763-767$.

33 de Vernejoul MC, Marie PJ. Cellules osseuses et remodelage osseux. Medecine/Sciences 1993; 9: $1192-1203$.

34 Rodan GA, Noda M. Gene expression in osteoblastic cells. Crit Rev Eukar Gene Exp 1991; 1: 85-98.

35 Goldring MB, Goldring SR. Skeletal tissue response to cytokines. Clin Ortho Related Res 1990; 258: 245 - 278

36 Fromigué O, Marie PJ, Lomri A. Differential effects of transforming growth factor $\beta 2$, dexamethasone and 1,25dihydroxyvitamine D on human bone marrow stromal cells. Cytokine 1997; 9: 613-623.

37 Cheng SL, et al. Differentiation of human bone marrow osteogenic stromal cells in vitro: induction of the osteoblast phenotype by dexamethasone. Endocrinology 1994; 134: $277-$ 286.

38 Subramaniam $\mathrm{M}$, et al. Glucocorticoid regulation of alkaline phosphatase, osteocalcin, and proto-oncogenes in normal human osteoblast-like cells. J Cell Biochem 1992; 50: $411-424$.

39 Trayhurn P, Hoggard N, Mercer J, Rayner D. Leptin: Fundamental aspects. Int J Obes Relat Metab Disord 1999; 23: $22-28$.

40 Casanueva F, Dieguez C. Interaction between body composition, leptin and growth hormone status. Bailliéres Clin Endocrinol Metab 1998; 12: $297-314$

41 Mantzoros CS. The role of leptin in human obesity and disease: A review of current evidence. Ann Intern Med 1999; 130: 671 680.

42 Ducy $\mathrm{P}$, et al. Leptin inhibits bone formation through a hypothalamic relay: a central control of bone mass. Cell 2000; 100: $197-207$.

43 Thomas T, et al. Leptin acts on human marrow stromal cells to enhance differentiation to osteoblasts and to inhibit differentiation to adipocytes. Endocrinology 1999; 140: 1630 - 1638. 
44 McCrory M, Wright N, Kilmer D. Nutritional aspects of neuromuscular diseases. Phys Med Rehabil Clin N Am 1998; 9: $127-143$.

45 Leroy-Willig A, et al. Body composition determined with MR in patients with Ducheme muscular dystrophy, spinal muscular dystrophy, and normal subjects. Magn Reson Imaging 1997; 15: $737-744$.

46 Kanda F, Fujii Y, Takahashi K, Fujita T. Dual-energy X-ray absorptiometry in neuromuscular diseases. Muscle Nerve 1994; 17: $431-435$.
47 Hancock D, Reed G, Atkinson P. Bone and soft tissue changes in paraplegic patients. Paraplegia 1979; 17: 267-271.

48 Meys E, et al. Bone remodeling markers and leptin after traumatic brain injury (TBI) complicated by prolonged vegetative state. J Bone Miner Res 1999; 14: S551. 